\title{
Paracentric inversion in the grasshopper Oedipoda charpentieri
}

\author{
J. Navas-Castillo, \\ J. Cabrero and \\ J. P. M. Camacho
}

\author{
Departamento de Biología Animal, Ecología y \\ Genética, Facultad de Ciencias, Universidad de \\ Granada, 18071 Granada, Spain.
}

\begin{abstract}
One out of ten adult males of the grasshopper Oedipoda charpentieri analysed from a natural population was heterozygous for a paracentric inversion in the megameric $M_{6}$ chromosome. The inversion involved changes in $C$ banding pattern which facilitated its detection. Meiotic behaviour was characterised by both an absence of inversion loops at prophase $I$ and dicentric bridges plus acentric fragments in anaphase $I$, so that this inversion could not have been detected using conventional staining techniques. The possible relationship between the scarcity of reports on paracentric inversions in natural populations of grasshoppers and difficulty to detect them is discussed.
\end{abstract}

\section{INTRODUCTION}

Paracentric inversions, contrary to pericentric ones, have been rarely reported in Orthoptera (see Hewitt, 1979), which is presumably due to the meiotic behaviour of the heteromorphic bivalents usually characterised by non homologous straight pairing between the standard and inverted segments at first meiotic prophase, and absence of dicentric bridges and acentric fragments at anaphase I. In this work we report the detection of a paracentric inversion by means of C-banding and silver impregnation techniques in a male of the grasshopper Oedipoda charpentieri.

\section{MATERIALS AND METHODS}

Ten adult males of Oedipoda charpentieri (Acrididae, Oedipodinae) were collected at Alcalá la Real (Jaén, Spain). Testes were fixed in (1:3) acetic acid: ethanol. C-banding was performed as described in Camacho et al. (1984) and silver impregnation was made using the technique described by Rufas et al. (1982).

\section{RESULTS AND DISCUSSION}

Oedipoda charpentieri standard males possess $2 n=$ $22+$ XO telocentric chromosomes. The $\mathbf{M}_{6}$ bivalent behaves as megameric unlike other species in this same genus, such as $O$. fuscocincta and $O$. coerulescens, in which the megameric bivalent is the $\mathrm{M}_{9}$ (Camacho et al., 1986). All chromosome pairs carry paracentromeric C-bands of various sizes. Furthermore, there are distal $C$-bands in the $\mathbf{M}_{6}$ and $M_{9}$ besides an interstitial small $C$-band in the $\mathbf{M}_{6}$. Silver staining demonstrated the presence of two nucleolar organising regions (NORs) associated with the interstitial and distal $\mathrm{C}$-bands on the $\mathrm{M}_{6}$ megameric chromosome (fig. 1). The existence of chromosomes with two NORs is of exceptional occurrence in grasshoppers since they had been hitherto observed only in Omocestus bolivari (Viseras and Camacho, 1984).

One out of ten males analysed was heterozygous for $C$-banding pattern in the $M_{6}$ pair. Thus, while one of both $\mathbf{M}_{6}$ chromosomes (B) appeared $\mathrm{C}$-banded like those in standard males, the other (I) had a small paracentromeric C-band and a large interstitial one, in contrast to $\mathrm{M}_{6}$ - B (figs. 2 and 3 ). Silver impregnation demonstrated the existence of two active NORs in the same positions as in standard males (figs. 4 and 5). These observations demonstrate the existence of a paracentric inversion which changed the position of the greater part of the paracentromeric C-band but did not change the location of the interstitial NOR. Thus, one of the break points was presumably located within the paracentromeric C-band near centromere and the other was adjacent to the interstitial C-band. Since the $\mathrm{M}_{6}$ bivalent possesses two 


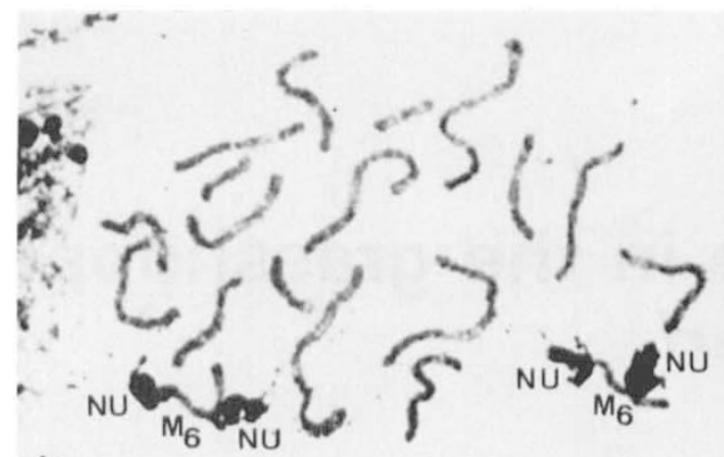

1
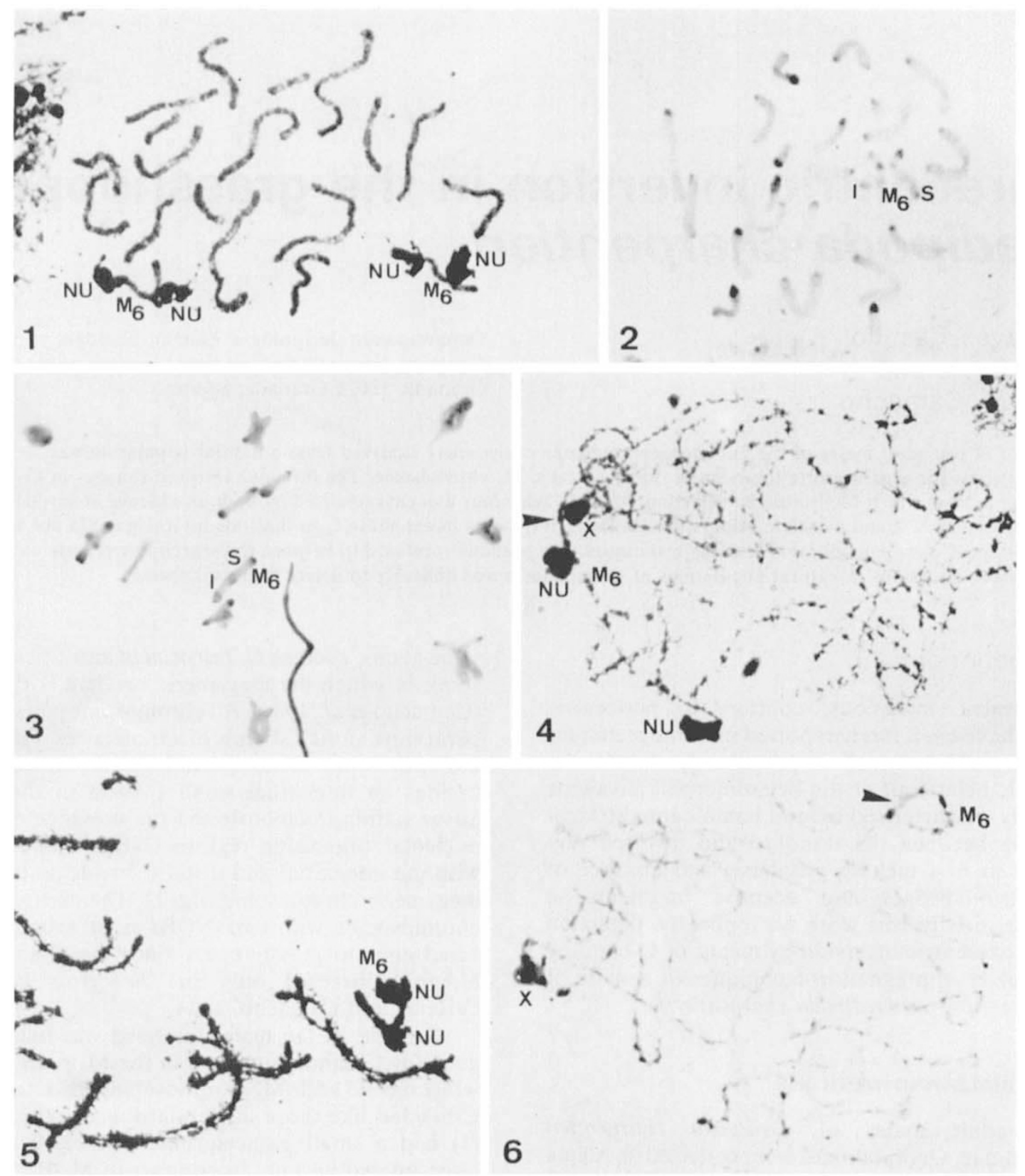

Figures 1-6 Paracentric inversion in a male of Oedipoda charpentieri. (1) Silver stained partial spermatogonial mitotic prometaphase showing two active NORs, one interstitial and one distal, in each $\mathbf{M}_{6}$ chromosome. (2) Spermatogonial mitotic metaphase showing the difference in C-banding pattern between the standard (S) and inverted (I) $\mathrm{M}_{6}$ chromosomes. (3) C-banded metaphase I cell showing the heteromorphic $\mathrm{M}_{6}$ bivalent with a single distal chiasma. (4) Silver stained zygotene cell from the same male showing straight non-homologous pairing in the zone of the inversion (arrowhead). (5) Silver stained partial pachytene cell showing a $V$ shaped $\mathrm{M}_{6}$ bivalent resulting from asynapsis in the zone of the inversion. (6) $\mathrm{C}$-banded zygotene cell showing a presumed reverse pairing loop (arrowhead). 
NORs, it could be easily identified in prophase I cells. Thus, in the great majority of zygotenepachytene cells the heteromorphic $\mathrm{M}_{6}$ bivalent showed non homologous straight pairing (fig. 4), in some cells it showed partial asynapsis (fig. 5) and in a single cell we observed a presumed inversion loop (fig. 6). The scarce anaphase I cells observed lacked dicentric bridges and acentric fragments. This meiotic behaviour is similar to that of other paracentric inversions described in Orthoptera (Nur, 1968; Haines et al., 1978). Thus, the scarcity of reverse pairing loops in prophase I and dicentric bridges with acentric fragments in anaphase $I$ is a severe obstacle for the detection of paracentric inversions in Orthoptera.

Several paracentric inversions, however, have been detected because they changed C-banding pattern, such as, for instance, that in the $\mathrm{X}$ chromosome of the South-East Queensland race of the grasshopper Caledia captiva (Shaw et al., 1976). Likewise, in the tettigoniid Baetica ustulata there exists an extensive chromosome polymorphism for C-heterochromatic blocks in the medium sized chromosomes (Fernández-Piqueras et al., 1984, Navas-Castillo et al., 1986), so that some chromosome variants can be related to each other by means of paracentric inversions. The paracentric inversion in the $\mathrm{M}_{6}$ chromosome of $O$. charpentieri described in this paper was detected because it produces a significant change in the C-banding pattern of this chromosome, but it would have presumably gone unnoticed because its meiotic behaviour was usually characterised by straight non-homologous pairing between the standard and inverted sequences.

A consequence of this structural mutation is the absence of chiasmata between standard and inverted segments. We have also observed consistently some males of Chorthippus jucundus and Ch. binotatus in which chiasmata frequently failed to form in one chromosome arm of a metacentric L-bivalent (figs. 7 and 8), and which could also be the result of cross-over suppression exerted by a paracentric inversion in that chromosome region. A similar explanation has been put forward by White (1973) to account for the observation in a morabine grasshopper of some individuals that lacked chiasmata in one arm of the metacentric $\mathrm{AB}$ bivalent, unlike the standard individuals which always have a chiasma in each $A B$ chromosome arm. Thus, it may be possible that many paracentric inversions remain undetected in grasshoppers simply because they do not involve heterochromatic regions and do not form inversion loops and dicentric bridges.

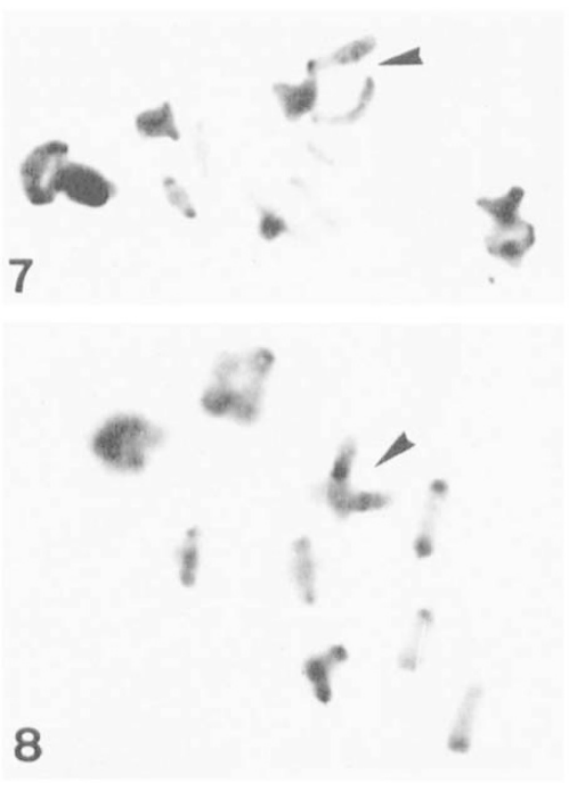

Figures 7 and 8 Absence of chiasmata in a whole arm of an L bivalent (arrowheads) in chorthippus jucundus (7) and Ch. binotatus (8).

Acknowledgements J.N.C. is grateful to Navas-Castillo family for their encouragement.

\section{REFERENCES}

CAMACHO, J. P. M., NAVAS-CASTILlo, J. AND CABRERO, J. 1986. Extra nucleolar activity associated with the presence of a supernumerary chromosome segment in the grasshopper Oedipoda fuscocincta. Heredity, 56, 237-241.

CAMACHO, J. P. M., VISERAS, E., NAVAS, J. AND CABRERO, J. 1984. C-heterochromatin content of supernumerary chromosome segments of grasshoppers: detection of an euchromatic extra segment. Heredity, 53, 167-175.

FERNANDEZ-PIQUERAS, J., RODRIGUEZ-CAMPOS, A., SENTISCASTAÑo, C. AND ROJO GARCIA, E. 1984. C-heterochromatin variation in the monospecific genus Baetica (Orthoptera: Tettigoniidae). Caryologia, 37, 69-76.

HAINES, R. L., ROBERTS, P. A. AND LATTIN, J. D. 1978. Paracentric inversion polymorphism in the grasshopper Boonacris alticola. Chromosoma, 65, 185-197.

HEWITT, G. M. 1979. Grasshoppers and crickets. Animal Cytogenetic, vol. 3. Insecta. 1. Orthoptera. Gebrüder Borntraeger, Berlin-Stuttgart.

NAVAS-CASTILlo, J., CABRERo, J. AND CAMACHO, J. P. M. 1986. Heterochromatin variants in Baetica ustulata (Orthoptera: Tettigoniidae) analysed by $\mathrm{C}$ and $\mathrm{G}$ banding. Heredity, 56, 161-165.

NUR, U. 1968. Synapsis and crossing over within a paracentric inversion in the grasshopper Camnula pellucida. Chromosoma, 25, 198-214. 
RUFAS, J. S. ITURRA, P., DE SOUZA, W. AND ESPONDA, P. 1982. Simple silver staining procedure for the localization of nucleolus and nucleolar organizer under light and electron microscopy. Arch. Biol., 93, 267-274.

SHAW, D. D., WEBB, G. C. AND WILKINSON, P. 1976. Population cytogenetics of the genus Caledia (Acrididae). II. Variation in the pattern of C-banding. Chromosoma, 56, 169-190.
VISERAS, E. AND CAMACHO, J. P. M. 1984. Polysomy in Omocestus bolivari: endophenotypic effects and suppression of nucleolar organizing region activity in the extra autosomes. Can. J. Genet. Cytol., 26, 547-556.

whiTe, M. J. D. 1973. Animal Cytology and Evolution, Third Edition, Cambridge Univ. Press. 